\title{
Metronomic chemotherapy in non-small cell lung cancer (Review)
}

\author{
YEFEI SHU $^{1 *}$, SHANSHAN WENG ${ }^{2 *}$ and SONG ZHENG ${ }^{1,3}$ \\ ${ }^{1}$ Department of Medical Oncology, Hangzhou Cancer Hospital, Hangzhou, Zhejiang 310002; \\ ${ }^{2}$ Department of Medical Oncology, The Second Affiliated Hospital of Zhejiang University School of Medicine, Hangzhou, \\ Zhejiang 310009; ${ }^{3}$ Department of Medical Oncology, Key Laboratory of Clinical Cancer Pharmacology and Toxicology \\ Research of Zhejiang, Affiliated Hangzhou First People's Hospital, Zhejiang University School of Medicine, \\ Hangzhou, Zhejiang 310006, P.R. China
}

Received November 3, 2019; Accepted July 15, 2020

DOI: $10.3892 / \mathrm{ol} .2020 .12170$

\begin{abstract}
Metronomic chemotherapy (MCT) is defined as the rhythmic chemotherapy of low-dose cytotoxic drugs with short or no drug-free breaks over prolonged periods. MCT affects tumor cells and the tumor microenvironment. Particularly, the low-dose schedule impairs the repair process of endothelial cells, resulting in an anti-angiogenesis effect. By stimulating the immune system to eliminate tumor cells, MCT induces immunological activation. Furthermore, combined with targeted therapy, anti-angiogenic drugs enhance the efficacy of MCT. The present review is an overview of phase I, II and III clinical trials focusing on the efficacy, toxicity and mechanism of MCT in patients with non-small cell lung cancer (NSCLC). Furthermore, the prospects of MCT in NSCLC have been discussed. The present review indicated that MCT is an efficacious treatment for selected patients with NSCLC, with acceptable systemic side effects and economic viability for public health.
\end{abstract}

\section{Contents}

1. Introduction

2. Preclinical studies of MCT

3. Clinical trials of $\mathrm{MCT}$

4. Mechanism of MCT

5. Conclusion

Correspondence to: Dr Song Zheng, Department of Medical Oncology, Hangzhou Cancer Hospital, 34 Yanguan Lane, Hangzhou, Zhejiang 310002, P.R. China

E-mail: tztree@126.com

${ }^{*}$ Contributed equally

Abbreviations: PFS, progression free survival; TTP, time to progression; OS, overall survival

Key words: metronomic chemotherapy, non-small cell lung cancer

\section{Introduction}

Lung cancer is one of the leading causes of cancer-related mortality worldwide, comprising an estimated $12-13 \%$ of total new cancer cases and 22-23\% of the total cancer-associated deaths in 2020 (1). A total of $\sim 85 \%$ of primary lung cancer cases are non-small cell lung cancer (NSCLC) (2) and the majority of patients are diagnosed at an advanced stage. With the exception of a few patients who may have the opportunity to receive immune checkpoint therapy and others with a drive gene mutation who can undergo targeted therapy, almost all patients with NSCLC undergo chemotherapy (3). Conventional chemotherapy attempts to use doses close to the maximum tolerated dose (MTD) to maximize efficacy and eradicate tumor cells directly and has been the cornerstone of standard cancer treatment for several decades $(4,5)$. Even with intensive chemotherapeutics, the overall response rate (ORR) of patients following first-line chemotherapy is $<10 \%$, progression-free survival (PFS) time is $\sim 2.5$ months and median overall survival (OS) time is $\sim 9$ months $(6,7)$. Therefore, a novel treatment that employs the periodic application of low-dose (one-tenth to one-third of MTD) cytotoxic drugs with short or no drug-free breaks (daily, several times a week or weekly) over prolonged periods, known as metronomic chemotherapy (MCT) (Fig. 1), is under investigation and has become a focus of research.

The present review collected publications using the terms 'metronomic chemotherapy', 'MCT' and 'NSCLC' to search the MEDLINE/PubMed database (http://www. webofknowledge.com/https://pubmed.ncbi.nlm.nih.gov) from January 2000 to December 2019. An overview of phase I, II and III clinical trials focusing on the efficacy, toxicity and mechanism of MCT in patients with NSCLC was conducted. The prospects of MCT in NSCLC have also been discussed. The current review indicated that MCT is an efficacious treatment option for selected patients with NSCLC, with acceptable systemic side effects and economic viability for public health.

\section{Preclinical studies of MCT}

The term 'metronomic' was first proposed by Hanahan et al (7) in 2000 based on studies by Browder et al (8) and 
Klement et al (9). In 2000, Browder et al established an animal xenograft model that underwent continuous application of low-dose cyclophosphamide, causing endothelial cells in the tumor vascular bed to continue to wither (8). In the same year, Klement et al also confirmed that continuous low-dose vinblastine inhibited tumor angiogenesis, leading to the recession of large, established tumors (9). Following these studies, the effect of MCT using numerous drugs has been gradually explored. The details preclinical drug studies are summarized in Table I.

\section{Clinical trials of MCT}

During the last decade, numerous clinical trials have been performed to explore MCT in first- and second-line treatment, and to investigate the maintenance of treatment for metastatic NSCLC (10-13). Drugs used by MCT-related clinical trials could be single-drug, two-drug or multiple-drug combinations, and can be combined with targeted drugs, anti-angiogenesis drugs or radiotherapy (Table II).

Single agent of MCT in first-line treatment. Despite evidence that carboplatin and paclitaxel significantly improved OS time compared with vinorelbine or gemcitabine monotherapy (median OS, 10.3 months vs. 6.2 months), greater toxicity limited their use (neutropenia, $48 \%$ vs. 12\%) (10). Single-agent chemotherapy is an option for patients who are less suited for combination chemotherapy, particularly for older patients, and an oral agent may be a more suitable choice of administration (14).

Metronomic oral vinorelbine is an extremely safe treatment for advanced NSCLC with notable clinical benefit, mainly consisting of long-term disease stabilization (15). Camerini et al (16) reported that the median survival of 14 patients with NSCLC who underwent MCT was $>30$ months. Compared with intravenous administration of vinorelbine, oral administration of vinorelbine has the advantages of convenience and minimal side effects (17). Patients with Union for International Cancer control version 8 stage IIIB-IV NSCLC who were treated with oral vinorelbine $50 \mathrm{mg} 3$ times/week as first-line chemotherapy had a median time to progression (TTP) of 5 months and a median OS of 9 months (range, 3-29 months), demonstrating good tolerance with rare incidents of serious toxicity $(16,18)$. Patients who were aged $>60$ years and had stage IIIB or IV, Eastern Cooperative Oncology Group (ECOG) $\geq 1$ and with $\geq 1$ significant comorbidity were treated with oral vinorelbine $30 \mathrm{mg} 3$ times/week or $40 \mathrm{mg} 3$ times/week, meaning treatment was administered 1 day on and 1 day off (19). The median OS was 12 months, disease control rate was $63 \%$ and median PFS was 9 months. A meta-analysis of metronomic oral vinorelbine encompassing 418 patients reported an OS of 8.7 months $(95 \%$ confidence interval, 7.6-9.5) (20). A schedule of 20-30 mg every other day without interruption demonstrated good tolerance and clinical benefit (21).

Taxanes (docetaxel and paclitaxel), which are novel microtubule-stabilizing agents, are an integral part of several commonly used chemotherapy regimens in NSCLC (22). Weekly docetaxel and 3-week conventional schemes exhibited similar effects for untreated advanced NSCLC $(23,24)$. In terms of adverse reactions, the febrile neutropenia incidence was significantly lower in the weekly metronomic treatment group compared with the traditional 3-week group.

Multiple MCT drugs in first-line treatment: Vinorelbine and cisplatin $(D D P)$. To evaluate the safety and efficacy of metronomic vinorelbine in combination with DDP as a first-line treatment for patients with advanced NSCLC, Katsaounis et al (25) conducted a multicenter phase II study, in which a total of 41 patients with advanced NSCLC were treated with oral metronomic vinorelbine $(60 \mathrm{mg}$ total dose, every other day) in combination with DDP $\left(80 \mathrm{mg} / \mathrm{m}^{2}\right)$ in cycles of 21 days. The median PFS was 4.2 months, median OS was 12.0 months and 1-year survival rate was $52.6 \%$. Three of these patients exhibited febrile neutropenia and one died due to sepsis. Although the combination schedule was accompanied by myelotoxicity, the treatment was still an effective option in the first-line treatment option for patients with advanced NSCLC. MTDs were reached at an oral dose of $60 \mathrm{mg} 3$ times/week for vinorelbine and $85 \mathrm{mg} / \mathrm{m}^{2}$ for DDP and ORR was $20.8 \%$. This metronomic strategy was tolerable and effective in patients with NSCLC (21).

Later line treatment. Oral metronomic vinorelbine produced non-negligible survival in elderly or pretreated patients and exhibited stable long-term blood concentrations $(21,26,27)$. Daily oral vinorelbine (30 mg/day) for 21 days with an interruption in treatment for 1 week was well tolerated without dose-limiting toxicity (26). In another study, a schedule of 20-30 mg every other day without interruption provided good tolerability and clinical benefit (21). Additionally, pretreated patients with NSCLC were treated with oral vinorelbine at a dose of $50 \mathrm{mg} 3$ times/week with a median OS of 9.4 months and a 1-year survival rate of $30.1 \%$ (27).

Single agent MCT in later line treatment: Taxane. In 2000, Hainsworth et al (28) concluded that weekly docetaxel $\left(36 \mathrm{mg} / \mathrm{m}^{2}\right)$ was well tolerated in elderly patients with NSCLC, with a median survival time of 5 months and a 1-year survival rate of $27 \%$. In another study, weekly paclitaxel $\left(80 \mathrm{mg} / \mathrm{m}^{2}\right)$ was also well tolerated, effective and safe for recurrent refractory NSCLC, with a median PFS of 4 months and a median OS of 7 months (29).

Single agent MCT in later line treatment: Temozolomide (TMZ). TMZ, a novel oral alkylating agent, has demonstrated anticancer activity against brain metastases in various solid tumors, including NSCLC (30). TMZ was administered at a dose of $75 \mathrm{mg} / \mathrm{m}^{2}$ daily for 21 days every 28 days, resulting in a median OS of 3.3 months and a 1-year survival rate of $22.5 \%$ (30). However, another phase II study reported no objective response to $\mathrm{TMZ}$ in patients with chemotherapy-naive advanced NSCLC (31). Treatment discontinuation may be the result of ineffective treatment in patients with NSCLC and a particularly poor prognosis.

Multiple MCT drugs in later line treatment. In 2006, Correale et al (32) conducted a pilot phase II study to evaluate the toxicity and effect of the novel metronomic protocol of weekly DDP $30 \mathrm{mg} / \mathrm{m}^{2}$ on days 1,8 and 14 and oral daily etoposide (VP16) $50 \mathrm{mg} / \mathrm{m}^{2}$ on day $1-21$ of the 28 days of the cycle in 


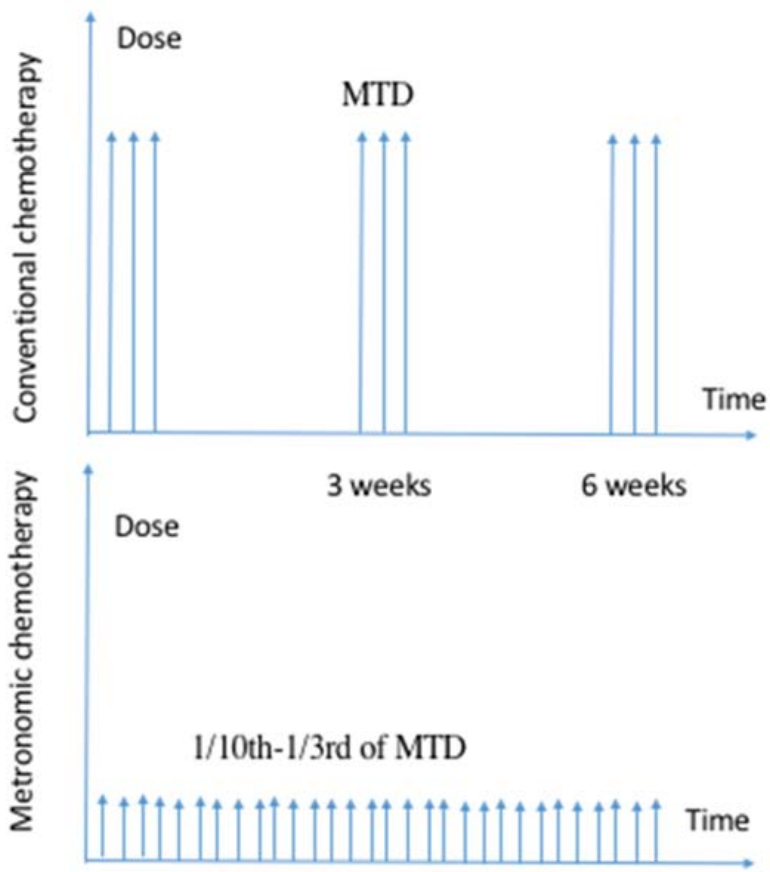

Daily, several times a week, or weekly

Figure 1. Difference between metronomic chemotherapy and conventional chemotherapy. MTD, maximum tolerated dose.

high-risk patients with NSCLC with a mean TTP of 9 months and OS of 13 months. However, three deaths were caused by pulmonary embolism. In the same study, 10 patients who underwent MCT exhibited decreased expression of vascular endothelial growth factor (VEGF), indicating that MCT may influence tumor growth and angiogenesis. Generally, MCT is well tolerated and effective, even for patients with poor general condition.

Docetaxel and trofosfamide. Gorn et al (11) conducted a pilot study investigating the combination of docetaxel $25 \mathrm{mg} / 2$ on days 1,8 and 15 , and trofosfamide $50 \mathrm{mg}$ daily every 28 days as a second-line treatment for patients with metastatic NSCLC. The median PFS and median OS were 2.9 and 6.9 months, respectively. Furthermore, no grade IV toxicity or treatment-induced death occurred.

MCT combined with target therapy. Targeted treatments yield higher response rates, longer PFS and prolonged OS compared with traditional cytotoxic chemotherapies (33). However, concurrent administration of gefitinib or erlotinib with standard platinum-doublet chemotherapy in large phase III randomized trials presented no improved survival compared with chemotherapy alone (34-37). It remains unclear whether MCT combined with targeted therapy yields clinical benefit.

Tegafur and gefitinib. Tegafur/uracil (UFT) has an underlying anti-angiogenesis effect and is suitable for MCT (38). This inhibitory effect is more obvious when UFT was administered continuously at low doses (39). For patients with epidermal growth factor receptor (EGFR) mutations, the addition of UFT significantly improved PFS (14.4 vs. 7.6 months) (39).
For patients with low microvessel density, the addition of UFT to gefitinib treatment resulted in longer PFS (median PFS, 11.8 vs. 2.8 months). The median OS was 18.3 months in the gefitinib alone group and 23.6 months in the gefitinib with UFT group.

Oral vinorelbine and erlotinib. Sutiman et al (40) designed a phase I study of oral vinorelbine in combination with erlotinib using conventional (CSV) and metronomic (MSV) dosing schedules in NSCLC to evaluate the safety, tolerability and pharmacokinetics of treatments. Oral vinorelbine $40 \mathrm{mg} / \mathrm{m}^{2}$ in the CSV group ( $\left.\mathrm{n}=16\right)$ and $100 \mathrm{mg} /$ week in the MSV group $(n=14)$ was administered on days 1 and 8 . An objective response was achieved in 38 and $29 \%$ of the CSV and MSV groups, respectively. In conclusion, the combination of oral vinorelbine with erlotinib was feasible and tolerable in both groups. Neither pharmacokinetic nor pharmacogenetic monitoring appeared to be useful in predicting OS with oral metronomic vinorelbine in advanced NSCLC (41). Metronomic vinorelbine inhibited the phosphorylation of extracellular signal-regulated kinase (ERK)1/ERK2 and protein kinase B, and significantly decreased the expression of cyclin-D1 and ATP-binding cassette super-family G member 2 mRNAs and proteins, sensitizing resistant cells to EGFR tyrosine kinase inhibitors (42).

MCT combined with anti-angiogenic drugs. Anti-angiogenic therapy has become a focus for the treatment of advanced lung cancer. Preclinical studies have demonstrated that the combination of MCT and anti-angiogenesis drugs can further improve efficacy $(43,44)$. Metronomic vinorelbine combined with Endostar significantly enhanced antitumor and anti-angiogenic responses without overt toxicity in a xenograft mouse model of human lung cancer (43).

Vinorelbine and sorafenib. Patients received a starting dose of sorafenib at $200 \mathrm{mg} 2$ times/day for 4 weeks with a fixed metronomic (3 times/week) dose of oral vinorelbine at 60,90 or $120 \mathrm{mg} /$ week (45). In patients without dose-limiting toxicities, sorafenib doses were increased to $400 \mathrm{mg} 2$ times/day for 4 weeks, $600 \mathrm{mg} 2$ times/day for 4 weeks and, finally, $800 \mathrm{mg} 2$ times/day. A total of 48 patients were analyzed. The results demonstrated that four (8.3\%) patients exhibited a partial response (PR) and seven $(14.6 \%)$ a cavitary response. The combination of sorafenib and metronomic oral vinorelbine was effective in treating advanced NSCLC. Furthermore, circulating endothelial cell counts were mentioned a promising marker for improved survival.

$D D P, V P 16$ and bevacizumab. A previous study of DDP and oral VP16 MCT combined with bevacizumab in the treatment of advanced NSCLC was performed to evaluate whether MCT increased the efficacy of anti-angiogenesis therapy (46). A total of 40 patients who received combination treatment had an ORR of $77.5 \%$. The stable disease rate was $15 \%$, median TTP was 7.6 months the most common grade $1-2$ toxicity was hematological toxicity. The study selected $5 \mathrm{mg} / \mathrm{kg}$ as the optimal biological dose of bevacizumab and $7.5 \mathrm{mg} / \mathrm{kg}$ as the maximum tolerated dose. Bevacizumab combined with MCT 
Table I. Preclinical studies of metronomic chemotherapy in lung cancer.

\begin{tabular}{|c|c|c|c|c|}
\hline First author, year & Protocol & Dosage & Xenograft & (Refs.) \\
\hline Browder et al, 2000 & Cyclophosphamide & $170 \mathrm{mg} / \mathrm{kg}$ every 6 days & Lewis lung carcinoma & (8) \\
\hline Eichhorn et al, 2010 & EndoTAG-1 with cisplatin & 40 and $80 \mathrm{mg} / \mathrm{kg} / \mathrm{day}$ & Lung cancer & (92) \\
\hline Panigraphy et al, 2010 & Oral etoposide & 40 and $80 \mathrm{mg} / \mathrm{kg} / \mathrm{day}$ & Lewis lung carcinoma & (93) \\
\hline Wang et al, 2012 & Cyclophosphamide and Endostar & $\begin{array}{l}10 \mathrm{mg} / \mathrm{kg} \text { of cyclophosphamide } \\
\text { and } 4 \mathrm{mg} / \mathrm{kg} \text { of Endostar daily }\end{array}$ & NSCLC & (44) \\
\hline
\end{tabular}

NSCLC, non-small cell lung cancer; EndoTAG-1, cationic lipid complexed paclitaxel.

was considered to be safe and feasible with anti-angiogenic activity and significant antitumor effects.

In 2011, Correale et al (47) added bevacizumab to DDP and applied metronomic daily oral VP16 for 45 patients with advanced NSCLC. The patients received DPP $\left(30 \mathrm{mg} / \mathrm{m}^{2}\right.$, days 1-3), oral VP16 (50 mg, days 1-15) and bevacizumab $(5 \mathrm{mg} / \mathrm{kg}$, day 3$)$ every 3 weeks. A PR was achieved in 31 $(68.9 \%)$ patients, NSCLC remained stable in eight (17.8\%) and disease progressed in six (13.3\%) patients. Furthermore, PFS was 9.53 months. The bio-chemotherapy regimen demonstrated efficacy in advanced NSCLC; however, due to hematological toxicity and gastroenteric toxicity, patients enrolled in future studies should be strictly selected.

Paclitaxel, gemcitabine and bevacizumab. The combination of paclitaxel, gemcitabine and bevacizumab administered in a metronomic schedule was demonstrated to be an effective and tolerable treatment strategy for patients with advanced NSCLC (44). Patients were treated with 4-week cycles of paclitaxel $80 \mathrm{mg} / \mathrm{m}^{2}$ and gemcitabine $300 \mathrm{mg} / \mathrm{m}^{2}$ weekly for three weeks, plus bevacizumab $10 \mathrm{mg} / \mathrm{kg}$ every two weeks. The results reported a median PFS of 8.5 months and a median OS of 25.5 months.

A phase II study of MCT with bevacizumab in patients with advanced non-squamous (NS)NSCLC was presented at the 2013 American Society of Clinical Oncology meeting (48). A total of 33 untreated patients with stage 4 NS-NSCLC were administrated a 4-week cycle of paclitaxel $\left(80 \mathrm{mg} / \mathrm{m}^{2}\right.$, days 1,8 and 15$)$, gemcitabine $\left(200-300 \mathrm{mg} / \mathrm{m}^{2}\right.$, days 1,8 and 15$)$ and bevacizumab $\left(10 \mathrm{mg} / \mathrm{m}^{2}\right.$, days 1 and 15$)$ for six cycles. The results reported that ORR was $73 \%$, median PFS was 9 months, median OS was 30 months, 1-year survival was $74 \%$ and 2-year survival was $55 \%$. The results, although limited by the size of the trial, were consistent with the hypothesis that MCT with bevacizumab may enhance anti-angiogenic effects and clinical benefits in advanced NS-NSCLC.

Metronomic cyclophosphamide with radiotherapy. Improving the outcomes of radiotherapy (RT) in the form of concurrent chemotherapy, anti-angiogenic therapy and anti-growth factor receptor targeted therapies has been a focus of research (49). Comparisons were made between 65 patients treated with palliative RT alone (20-30 Gy in 5-10 fractions) and 74 patients treated with palliative RT and oral metronomic cyclophosphamide (50 mg daily) (50). The PFS was significantly higher when metronomic chemotherapy was added to $\mathrm{RT}$ in comparison to treatment with RT alone in patients with adenocarcinoma (3.5 vs. 2.4 months) and no significant differences were observed in patients with squamous cell carcinoma without any measurable hematological toxicity. Radiotherapy combined with metronomic VP16 prolonged OS, indicating that the combination may have a synergistic effect (51).

Maintenance therapy. Based on the characteristics of MCT (low toxicity, high efficacy and low resistance to chemotherapy), its combination with other drugs, including targeted therapy, is a choice of treatment for advanced NSCLC $(12,13)$. Currently, two phase III studies have confirmed the promising efficacy of MCT with maintenance therapy $(12,13)$. After the tumor load is decreased by traditional chemotherapy, MCT may have improved function in inhibiting tumor angiogenesis and adjusting the immune function in maintenance therapy $(52,53)$. However, chemotherapy conversion for NSCLC still requires basic and clinical verification.

A larger number of severe toxicities, including grade 4 hemoptysis, thromboembolism and pulmonary embolism, were observed in MCT combined with targeted therapy, such as bevacizumab and sunitinib (54). TMZ and VP16 MCT are associated with a risk of myelodysplastic and secondary leukemia $(55,56)$. PFS reached 4 months following second-line metronomic oral vinorelbine-atezolizumab combination for stage-IV NSCLC (57). Additional attention should be paid to the cumulative and long-term toxicity in long-term use of MCT, particularly in children. Furthermore, maintenance therapy with oral metronomic vinorelbine prolonged PFS compared with best supportive care; however, the optimal dose of oral metronomic vinorelbine requires further investigation (58).

\section{Mechanism of MCT}

Continuous low-dose chemotherapy was shown to achieve more antitumor effects in vivo compared with routine chemotherapy with a completely different mechanism, laying the foundation for MCT (8). In early 2000, a relatively low dose of cyclophosphamide or vinblastine was used to validate the inhibition of angiogenesis inhibition and how that exerts an antitumor effect in an animal model (8). Additionally, several novel mechanisms have been identified, including immune- and stem cell-based mechanisms (Fig. 2) (59-61). 


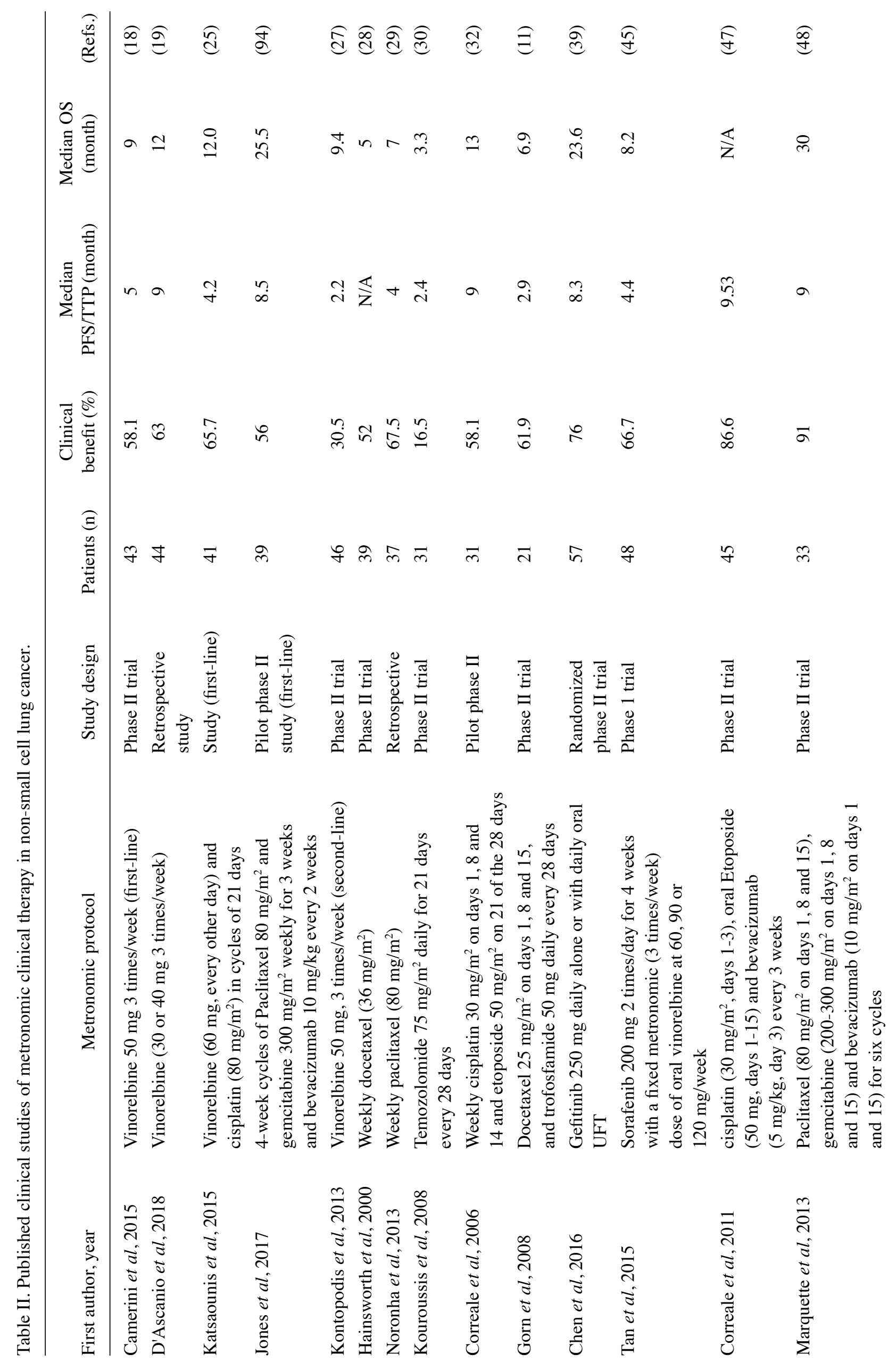


Angiogenesis mechanism. MCT is hypothesized to target endothelial cells and circulating endothelial progenitors (CEPs) directly with a lack of drug resistance $(38,62)$. Bocci et al $(63)$ reported almost no difference among various endothelial cells and cancer cells during short-term exposure to cytotoxic drugs. However, following long-term continuous exposure, endothelial cells were relatively more sensitive compared with cancer cells (63). Owing to the high sensitivity of tumor endothelial cells, low doses of chemotherapy drugs inhibit their proliferation instead of the proliferation cancer cells $(63,64)$. Additionally, cyclophosphamide MCT reduced the number and activity of CEPs, coinciding with long-term tumor inhibition (65). It has been reported that low-dose MCT may be an effective treatment to prevent CEPs mobilization (66). Furthermore, MCT induces functional normalization of tumor blood vessels, resulting in improved tumor perfusion (66). Consequently, MCT delays both primary and secondary tumor growth by blocking the supply of essential nutrients and removing metabolites $(38,67,68)$. Vinorelbine MCT combined with an angiogenesis inhibitor (Endostar) significantly enhanced anti-angiogenic responses by inhibiting tumor growth by decreasing the expression of cluster of differentiation (CD) 31, VEGF, hypoxia inducible factor $1 \alpha$ and CEPs in a xenograft model of human lung cancer (43).

Immune-based mechanism. In addition to angiogenesis inhibition, MCT also restores antitumor immunity and induces tumor dormancy (69), forming a tumor immune balance from an immunosuppressive state to an immune activation state (70).

Regulatory $\mathrm{T}$ cells (Tregs) are CD4+CD25+ forkhead box P3+ lymphocytes and the expression of cytotoxic lymphocyte-associated antigen-4 inhibits cell-specific immune responses (71,72). Tregs inhibit the antitumor immune response, which is mediated by $\mathrm{CD} 8+$ lymphocytes, CD4+ $\mathrm{T}$ helper cells and natural killer cells (72-74). Increased levels of Tregs are associated with tumor progression and a lack of response to cancer therapy (74). Therefore, the removal of Tregs from patients with NSCLC, particularly those in the tumor microenvironment, is considered important for successful antitumor therapy (74). Banissi et al (74) observed a decreased Treg/CD4+ ratio and attenuated residual Treg immunity suppression ability in a TMZ-resistant glioma model with TMZ MCT (75). Furthermore, Ghiringhelli et al (76) confirmed that Tregs suppress NK cell effector functions in vitro and in vivo, i.e. homeostatic proliferation, cytotoxicity and IL-12-mediated IFN- $\gamma$ production.

Another subset of tumor suppressor cells, known as myeloid-derived suppressor cells (MDSC), inhibit the activity of $\mathrm{T}$ cells in mouse tumor cell line 4T1-Neu (77). The reduction of MDSCs was hypothesized to be associated with the inhibition of p38 mitogen-activated protein kinase activity, decreased levels of tumor necrosis factor- $\alpha$ and NO and inhibition of S100 calcium-binding protein A9 expression (77). Furthermore, MCT has been reported to selectively eliminate MDSCs and the protection of T-cell subsets, thereby enhancing anti-tumor immunity (77). An in vivo study indicated that paclitaxel MCT reduced MDSC infiltration in tumor tissues and that there was no effect on bone marrow hematopoietic stem cells (78). 


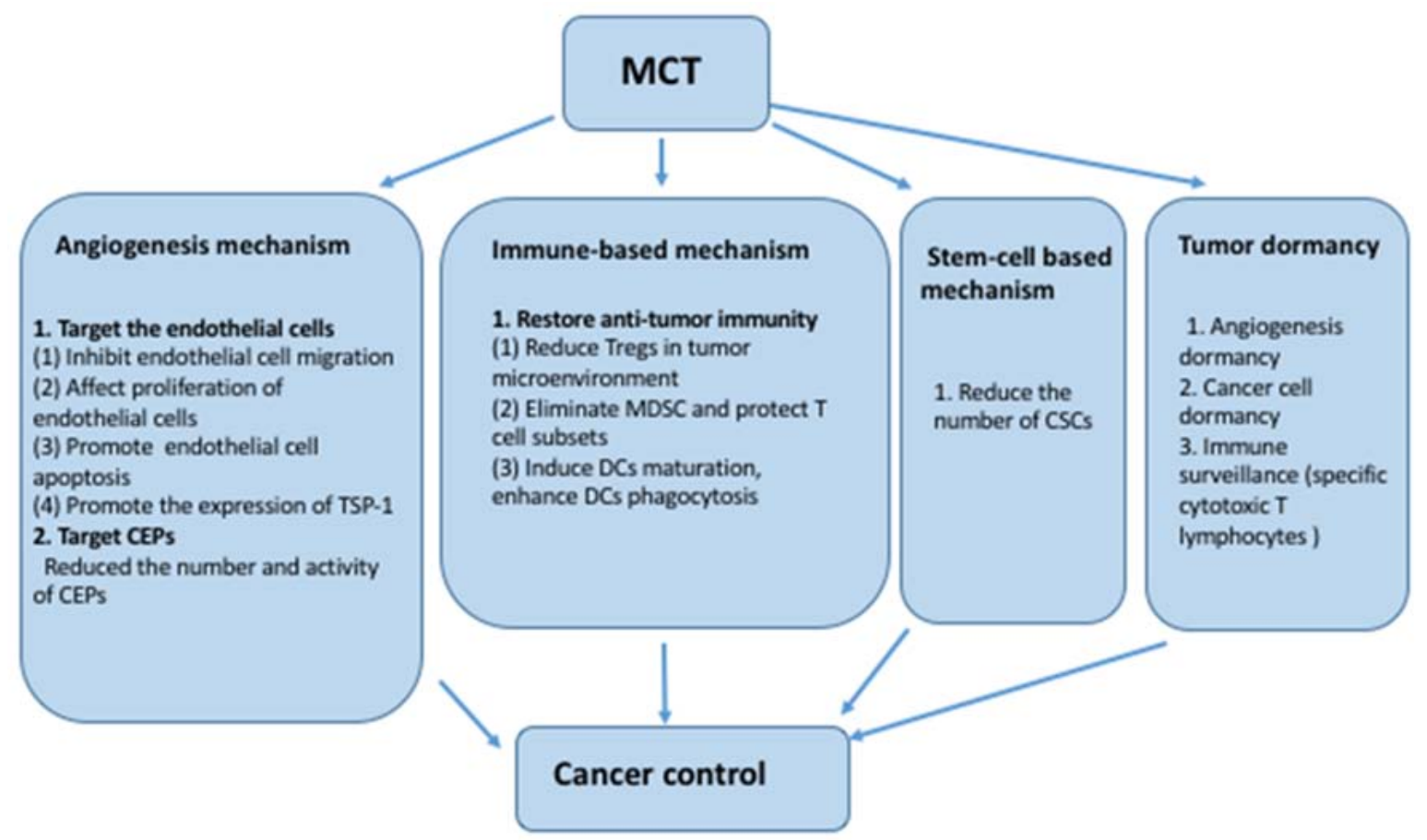

Figure 2. Mechanism of metronomic chemotherapy. MCT, metronomic chemotherapy; TSP-1, thrombospondin 1; CEPs, circulating endothelial progenitors; Tregs, regulatory T cells; MDSC, myeloid-derived suppressor cells; DCs, dendritic cells; CSCs, cancer stem cells.

As antigen-presenting cells, immunotherapy-based dendritic cells (DCs) have been shown to preclinically and clinically induce a strong antitumor immune response (79). This study demonstrated that MCT induced DC maturation, enhanced DC phagocytosis and activated the Rho family of guanosine triphosphate phosphatases on DCs, which regulate cell-cell interactions, cell migration and endocytosis (80). MCT regimens of certain chemotherapeutic drugs, including vinblastine, paclitaxel and VP16, promoted DC maturation at non-toxic concentrations (62). In a clinical setting, optimization of exact dosage and timing may need to be adjusted with respect to the patient's immune response and the type of tumor (81).

Stem cell-based mechanism. Cancer stem cells (CSCs) are a group of cells with persistent self-renewal and unlimited proliferation capacities in tumors, triggering resistance to conventional chemotherapy (82). Cyclophosphamide MCT has been demonstrated to significantly impair primary and metastatic tumor formation (83) and decrease the number of CD133+ precursors $\mathrm{CD} 133+/ \mathrm{CD} 44+/ \mathrm{CD} 24+$ in a pancreatic cancer xenograft model (84). Furthermore, an in vivo study indicated that the tumorigenicity of these resistant cells' tumorigenicity decreased with significant depletion of parental CD44+ cells, indicating that MCT may target CD44+ CSCs (85).

Tumor dormancy. Previous studies have identified the important effect that tumor cell dormancy serves in inhibiting tumor progression and recurrence $(86,87)$. Tumor dormancy can occur at primary and metastatic tumor sites and is usually divided into three different types: i) Angiogenesis dormancy; ii) cell dormancy and iii) immune surveillance $(69,88)$. Following induced apoptosis of tumor cells by tumor-specific cytotoxic
T lymphocytes, residual tumor cells usually survive; however, the immune system ensures that the tumor cells remain in a dormant state until immune escape occurs, followed by dormancy interruption (89).

\section{Conclusion}

The current review summarized preclinical and clinical trials focused on evaluating MCT either alone or in combination with other treatments in NSCLC management and provided information about the underlying mechanisms. Whether MCT is as efficient as conventional chemotherapy in front-line settings and whether it is a good surrogate for further line treatment in NSCLC has not been not fully demonstrated, particularly in the field of targeted therapy and immune therapy. MCT demonstrated promise in the treatment of NSCLC; however, the current data cannot truly verify its superiority to conventional chemotherapy. Nonetheless, due to lower toxicity, higher tolerability and relatively acceptable efficacy of MCT compared with supportive care, further investigation of MCT in NSCLC is required as MCT may be an optimal option in further line treatments for patients who cannot tolerate conventional chemotherapy, even in front-line settings.

MCT was originally developed to overcome drug resistance by shifting the therapeutic target from tumor cells to the tumor vasculature. The therapy can be personalized as it has been combined with targeted drugs and immune checkpoint inhibitors (90). Notably, 'personalization' should be emphasized as precision medicine takes into account the personal, familial and economic aspects of patient care to provide customized treatment (70).

To the best of our knowledge, the current review is the first systematic review of MCT in NSCLC. Although MCT has 
been a focus of research in recent years, numerous aspects of MCT remain empirical or unresolved. Considering the reported data were extracted from relatively small phase II trials, further studies are required to investigate MCT, including the most suitable drugs, doses of each drug, reasonable frequency, duration and suitable patients. Furthermore, future head-to-head studies are required to determine which scheme is better. Biomarkers are needed to derive the optimal metronomic dosing of cytotoxic agents (91). Monitoring and evaluating the effect of MCT remains worthy of further investigation.

\section{Acknowledgements}

Not applicable.

\section{Funding}

The current review was funded by the National Natural Science Foundation of China (grant no. 81372660), Key Medical Science Research Fund of Hangzhou (grant no. 2011ZD001), Medical Science Research Fund of Zhejiang Province (grant no. 2013KYA157), Traditional Chinese Medicine Science and Technology Project of Zhejiang Province (grant no. 2013ZA104), Zhejiang Province Public Welfare Technology Application Research Project (grant no. 2017C33200) and Hangzhou Science and Technology Bureau grant no. (20140633B30).

\section{Availability of data and materials}

The datasets generated and/or analyzed during the present study are available in the MEDLINE/PubMed database (http://www. webofknowledge.com/https://pubmed.ncbi.nlm.nih.gov).

\section{Author's contributions}

YS supervised the project and wrote the original draft of the manuscript. SW conceptualized the current review. SZ reviewed and edited the manuscript. All the authors have read and approved the manuscript.

\section{Ethics approval and consent to participate}

Not applicable.

\section{Patient consent for publication}

Not applicable.

\section{Competing interests}

The authors declare that they have no competing interests.

\section{References}

1. Siegel RL, Miller KD and Jemal A: Cancer statistics, 2020. CA Cancer J Clin 70: 7-30, 2020.

2. Tessen HW, Hutzschenreuter U, Steffens CC, et al: The treatment of lung cancer in German outpatient centres. Data from a clinical registry-TLK Registry. Onkologie 34: 153-153, 2011.
3. Herbst RS, Morgensztern D and Boshoff C: The biology and management of non-small cell lung cancer. Nature 553: 446-454, 2018.

4. Torimura T, Iwamoto H, Nakamura T, Koga H, Ueno T, Kerbel RS and Sata M: Metronomic chemotherapy: Possible clinical application in advanced hepatocellular carcinoma. Transl Oncol 6: 511-519, 2013.

5. Benzekry S, Pasquier E, Barbolosi D, Lacarelle B, Barlési F André N and Ciccolini J: Metronomic reloaded: Theoretical models bringing chemotherapy into the era of precision medicine. Semin Cancer Biol 35: 53-61, 2015.

6. Weiss JM and Stinchcombe TE: Second-line therapy for advanced NSCLC. Oncologist 18: 947-953, 2013.

7. Zhang S, Liu J and Cheng Y: Metronomic chemotherapy-A new path to treat advanced non-small cell lung cancer. Zhongguo Fei Ai Za Zhi 18: 232-239, 2015 (In Chinese)

8. Browder T, Butterfield CE, Kraling BM, Shi B, Marshall B, O'Reilly MS and Folkman J: Antiangiogenic scheduling of chemotherapy improves efficacy against experimental drug-resistant cancer. Cancer Res 60: 1878-1886, 2000.

9. Klement G, Baruchel S, Rak J, Man S, Clark K, Hicklin DJ, Bohlen P and Kerbel RS: Continuous low-dose therapy with vinblastine and VEGF receptor-2 antibody induces sustained tumor regression without overt toxicity. J Clin Invest 105: R15-R24, 2000.

10. Quoix E, Zalcman G, Oster JP, Westeel V, Pichon E, Lavolé A, Dauba J, Debieuvre D, Souquet PJ, Bigay-Game L, et al: Carboplatin and weekly paclitaxel doublet chemotherapy compared with monotherapy in elderly patients with advanced non-small-cell lung cancer: IFCT-0501 randomised, phase 3 trial. Lancet 378: 1079-1088, 2011.

11. Görn M, Habermann CR, Anige M, Thöm I, Schuch G, Andritzky B, Brandl S, Burkholder I, Edler L, Hossfeld DK, et al: A pilot study of docetaxel and trofosfamide as second-line 'metronomic' chemotherapy in the treatment of metastatic non-small cell lung cancer (NSCLC). Onkologie 31: 185-189, 2008.

12. Belani CP, Barstis J, Perry MC, La Rocca RV, Nattam SR, Rinaldi D, Clark R and Mills GM: Multicenter, randomized trial for stage IIIB or IV non-small-cell lung cancer using weekly paclitaxel and carboplatin followed by maintenance weekly paclitaxel or observation. J Clin Oncol 21: 2933-2939, 2003.

13. Schuette W, Blankenburg T, Guschall W, Dittrich I, Schroeder M, Schweisfurth H, Chemaissani A, Schumann C, Dickgreber N, Appel $\mathrm{T}$ and Ukena $\mathrm{D}$ : Multicenter randomized trial for stage IIIB/IV non-small-cell lung cancer using every-3-week versus weekly paclitaxel/carboplatin. Clin Lung Cancer 7: 338-343, 2006.

14. Biganzoli L, Lichtman S, Michel JP, Papamichael D, Quoix E, Walko $\mathrm{C}$ and Aapro M: Oral single-agent chemotherapy in older patients with solid tumours: A position paper from the International Society of Geriatric Oncology (SIOG). Eur J Cancer 51: 2491-2500, 2015.

15. Camerini A, Banna GL, Cinieri S, Pezzuto A, Mencoboni M, Rosetti F, Figueiredo A, Rizzo P, Ricci A, Langenhoven L, et al: Metronomic oral vinorelbine for the treatment of advanced non-small cell lung cancer: A multicenter international retrospective analysis. Clin Transl Oncol 21: 790-795, 2019.

16. Camerini A, Valsuani C, Mazzoni F, Siclari O, Puccetti C, Donati S, Rondini M, Tartarelli G, Puccinelli P, Di Costanzo F and Amoroso D: Phase II trial of single-agent oral vinorelbine in elderly ( $>$ or $=70$ years) patients with advanced non-small-cell lung cancer and poor performance status. Ann Oncol 21: 1290-1295, 2010.

17. Jassem J, Ramlau R, Karnicka-Mlodkowska H, Krawczyk K, Krzakowski M, Zatloukal P, Lemarié E, Hartmann W, Novakova L, O'Brien M and Depierr A: A multicenter randomized phase II study of oral vs. intravenous vinorelbine in advanced non-small-cell lung cancer patients. Ann Oncol 12: 1375-1381, 2001

18. Camerini A, Puccetti C, Donati S, Valsuani C, Petrella MC, Tartarelli G, Puccinelli P and Amoroso D: Metronomic oral vinorelbine as first-line treatment in elderly patients with advanced non-small cell lung cancer: Results of a phase II trial (MOVE trial). BMC Cancer 15: 359, 2015.

19. D'Ascanio M, Pezzuto A, Fiorentino C, Sposato B, Bruno P, Grieco A, Mancini R and Ricci A: Metronomic chemotherapy with vinorelbine produces clinical benefit and low toxicity in frail elderly patients affected by advanced non-small cell lung cancer. Biomed Res Int 2018: 6278403, 2018. 
20. Pujol JL, Coffy A, Camerini A, Kotsakis A, Mencoboni M, Gusella M, Pasini F, Pezzuto A, Banna GL, Bilir C, et al: An individual patient-data meta-analysis of metronomic oral vinorelbine in metastatic non-small cell lung cancer. PLoS One 14: e0220988, 2019.

21. Pasini F, Barile C, Caruso D, Modena Y, Fraccon AP, Bertolaso L, Menon D, La Russa F, Crepaldi G, Bononi A, et al: Oral metronomic vinorelbine (OMV) in elderly or pretreated patients with advanced non small cell lung cancer: Outcome and pharmacokinetics in the real world. Invest New Drugs 36: 927-932, 2018.

22. Huizing MT, Misser VH, Pieters RC, ten Bokkel Huinink WW, Veenhof $\mathrm{CH}$, Vermorken JB, Pinedo HM and Beijnen JH: Taxanes: A new class of antitumor agents. Cancer Invest 13: 381-404, 1995.

23. Gervais R, Ducolone A, Breton JL, Braun D, Lebeau B, Vaylet F, Debieuvre D, Pujol JL, Tredaniel J, Clouet P and Quoix E: Phase II randomised trial comparing docetaxel given every 3 weeks with weekly schedule as second-line therapy in patients with advanced non-small-cell lung cancer (NSCLC). Ann Oncol 16: 90-96, 2005.

24. Camps C, Massuti B, Jimenez A, Maestu I, Gómez RG, Isla D, González JL, Almenar D, Blasco A, Rosell R, et al: Randomized phase III study of 3-weekly versus weekly docetaxel in pretreated advanced non-small-cell lung cancer: A Spanish Lung Cancer Group trial. Ann Oncol 17: 467-472, 2006.

25. Katsaounis P, Kotsakis A, Agelaki S, Kontopodis E, Agelidou A, Kentepozidis N, Vamvakas L, Christopoulou A, Karachaliou N, Hatzidaki D and Georgoulias V: Cisplatin in combination with metronomic vinorelbine as front-line treatment in advanced non-small cell lung cancer: A multicenter phase II study of the Hellenic Oncology Research Group (HORG). Cancer Chemother Pharmacol 75: 821-827, 2015.

26. Bozec A, Fischel JL and Milano G: Epidermal growth factor receptor/angiogenesis dual targeting: preclinical experience. Curr Opin Oncol 18: 330-334, 2006.

27. Kontopodis E, Hatzidaki D, Varthalitis I, Kentepozidis N, Giassas S, Pantazopoulos N, Vardakis N, Rovithi M, Georgoulias V and Agelaki S: A phase II study of metronomic oral vinorelbine administered in the second line and beyond in non-small cell lung cancer (NSCLC): A phase II study of the Hellenic Oncology Research Group. J Chemotherapy 25: 49-55, 2013.

28. Hainsworth JD, Burris HA III, Litchy S, Morrissey LH, Barton JH, Bradof JE and Greco FA: Weekly docetaxel in the treatment of elderly patients with advanced nonsmall cell lung carcinoma. A Minnie Pearl Cancer Research Network Phase II Trial. Cancer 89: 328-333, 2000.

29. Noronha V, Patil VM, Joshi A and Prabhash K: Efficacy and safety of metronomic administration of paclitaxel for advanced recurrent non-small-cell lung cancer. Indian J Cancer 50: 122-127, 2013

30. Kouroussis C, Vamvakas L, Vardakis N, Kotsakis A, Kalykaki A, Kalbakis K, Saridaki Z, Kentepozidis N, Giassas S and Georgoulias V: Continuous administration of daily low-dose temozolomide in pretreated patients with advanced non-small cell lung cancer: A phase II study. Oncology 76: 112-117, 2009.

31. Dziadziuszko R, Ardizzoni A, Postmus PE, Smit EF, Price A, Debruyne C, Legrand C and Giaccone G; EORTC Lung Cancer Group: Temozolomide in patients with advanced non-small cell lung cancer with and without brain metastases: A phase II study of the EORTC Lung Cancer Group (08965). Eur J Cancer 39: 1271-1276, 2003

32. Correale P, Cerretani D, Remondo C, Martellucci I, Marsili S, La Placa M, Sciandivasci A, Paolelli L, Pascucci A, Rossi M, et al: A novel metronomic chemotherapy regimen of weekly platinum and daily oral etoposide in high-risk non-small cell lung cancer patients. Oncol Rep 16: 133-140, 2006.

33. Hirsch FR, Suda K, Wiens J and Bunn PA Jr: New and emerging targeted treatments in advanced non-small-cell lung cancer. Lancet 388: 1012-1024, 2016

34. Giaccone G, Herbst RS, Manegold C, Scagliotti G, Rosell R, Miller V, Natale RB, Schiller JH, Von Pawel J, Pluzanska A, et al: Gefitinib in combination with gemcitabine and cisplatin in advanced non-small-cell lung cancer: A phase III trial-INTACT 1. J Clin Oncol 22: 777-784, 2004

35. Herbst RS, Giaccone G, Schiller JH, Natale RB, Miller V, Manegold C, Scagliotti G, Rosell R, Oliff I, Reeves JA, et al: Gefitinib in combination with paclitaxel and carboplatin in advanced non-small-cell lung cancer: A phase III trial-INTACT 2. J Clin Oncol 22: 785-794, 2004
36. Herbst RS, Prager D, Hermann R, Fehrenbacher L, Johnson BE, Sandler A, Kris MG, Tran HT, Klein P, Li X, et al: TRIBUTE: A phase III trial of erlotinib hydrochloride (OSI-774) combined with carboplatin and paclitaxel chemotherapy in advanced non-small-cell lung cancer. J Clin Oncol 23: 5892-5899, 2005.

37. Gatzemeier U, Pluzanska A, Szczesna A, Kaukel E, Roubec J, De Rosa F, Milanowski J, Karnicka-Mlodkowski H, Pesek M, Serwatowski P, et al: Phase III study of erlotinib in combination with cisplatin and gemcitabine in advanced non-small-cell lung cancer: The Tarceva Lung Cancer Investigation Trial. J Clin Oncol 25: 1545-1552, 2007.

38. Kerbel RS and Kamen BA: The anti-angiogenic basis of metronomic chemotherapy. Nat Rev Cancer 4: 423-436, 2004

39. Chen YM, Fan WC, Tsai CM, Liu SH, Shih JF, Chou TY, Wu CH, Chou KT, Lee YC, Perng RP, et al: A Phase II randomized trial of gefitinib alone or with tegafur/uracil treatment in patients with pulmonary adenocarcinoma who had failed previous chemotherapy. J Thorac Oncol 6: 1110-1116, 2011.

40. Sutiman N, Zhang ZX, Tan EH, Ang MK, Tan SW, Toh CK, $\mathrm{Ng}$ QS, Chowbay B and Lim WT: Phase I study of oral vinorelbine in combination with erlotinib in advanced non-small cell lung cancer (NSCLC) using two different schedules. PLoS One 11: e0154316, 2016

41. Gusella M, Pasini F, Caruso D, Barile C, Modena Y, Fraccon AP, Bertolaso L, Menon D, Crepaldi G, Bononi A, et al: Clinical outcomes of oral metronomic vinorelbine in advanced non-small cell lung cancer: Correlations with pharmacokinetics and MDR1 polymorphisms. Cancer Chemother Pharmacol 83: 493-500, 2019.

42. Orlandi P, Di Desidero T, Salvia G, Muscatello B, Francia G and Bocci G: Metronomic vinorelbine is directly active on non small cell lung cancer cells and sensitizes the EGFR(L858R/T790M) cells to reversible EGFR tyrosine kinase inhibitors. Biochem Pharmacol 152: 327-337, 2018.

43. Qin RS, Zhang ZH, Zhu NP, Chen F, Guo Q, Hu HW, Fu SZ, Liu SS, Chen Y, Fan J and Han YW: Enhanced antitumor and anti-angiogenic effects of metronomic Vinorelbine combined with Endostar on Lewis lung carcinoma. BMC Cancer 18: 967, 2018.

44. Wang R, Qin S, Chen Y, Li Y, Chen C, Wang Z, Zheng R and Wu Q: Enhanced anti-tumor and anti-angiogenic effects of metronomic cyclophosphamide combined with Endostar in a xenograft model of human lung cancer. Oncol Rep 28: 439-445, 2012.

45. Tan EH, Tan DS, Li WY, Haaland B, Ang MK, Chau NM, Toh CK, Tan IB, Koh TS, Thng CH, et al: Metronomic vinorelbine (oral) in combination with sorafenib in advanced non-small cell lung cancer. Lung Cancer 88: 289-296, 2015.

46. Correale P, Remondo C, Carbone SF, Ricci V, Migali C, Martellucci I, Licchetta A, Addeo R, Volterrani L, Gotti G, et al: Dose/dense metronomic chemotherapy with fractioned cisplatin and oral daily etoposide enhances the anti-angiogenic effects of bevacizumab and has strong antitumor activity in advanced non-small-cell-lung cancer patients. Cancer Biol Ther 9: 685-693, 2010

47. Correale P, Botta C, Basile A, Pagliuchi M, Licchetta A, Martellucci I, Bestoso E, Apollinari S, Addeo R, Misso G, et al: Phase II trial of bevacizumab and dose/dense chemotherapy with cisplatin and metronomic daily oral etoposide in advanced non-small-cell-lung cancer patients. Cancer Biol Ther 12: 112-118, 2011.

48. Marquette CL, Grant SC, DeShazo M, Reddy V, Cantor A, MileyMary Jerome D and Robert F: Phase II study of metronomic chemotherapy (MC) with bevacizumab (B) in patients (Pts) with advanced (Adv) nonsquamous non-small cell lung cancer (NS-NSCLC). J Clin Oncol 31 (15 Suppl): S8057, 2013.

49. Revannasiddaiah S and Susheela SP: Chemically enhanced radiotherapy: Visions for the future. Ann Transl Med 4: 52, 2016.

50. Revannasiddaiah S, Joshi SC, Pandey KC, Rastogi M, Sharma $\mathrm{M}$ and Gupta $\mathrm{M}$ : The results with the addition of metronomic cyclophosphamide to palliative radiotherapy for the treatment of non-small cell lung carcinoma. Ann Trans Med 3: 305, 2015

51. Pastina P, Nardone V, Botta C, Croci S, Tini P, Battaglia G, Ricci V, Cusi MG, Gandolfo C, Misso G, et al: Radiotherapy prolongs the survival of advanced non-small-cell lung cancer patients undergone to an immune-modulating treatment with dose-fractioned cisplatin and metronomic etoposide and bevacizumab (mPEBev). Oncotarget 8: 75904-75913, 2017. 
52. Moserle L, Amadori A and Indraccolo S: The angiogenic Switch: Implications in the regulation of tumor dormancy. Curr Mol Med 9: 935-941, 2009.

53. Bergers $\mathrm{G}$ and Benjamin LE: Tumorigenesis and the angiogenic switch. Nat Rev Cancer 3: 401-410, 2003.

54. Correale P, Remondo C, Carbone SF, Ricci V, Migali C, Martellucci I, Licchetta A, Addeo R, Volterrani L, Gotti G, et al: Dose/dense metronomic chemotherapy with fractioned cisplatin and oral daily etoposide enhances the anti-angiogenic effects of bevacizumab and has strong antitumor activity in advanced non-small-cell-lung cancer patients. Cancer Biol Ther 9: 685-693, 2010

55. Shaikh AJ and Masood N: Acute lymphoblastic leukemia subsequent to temozolomide use in a 26-year-old man: A case report. J Med Case Rep 4: 274, 2010.

56. Le Deley MC, Leblanc T, Shamsaldin A, Raquin MA, Lacour B, Sommelet D, Chompret A, Cayuela JM, Bayle C Bernheim A, et al: Risk of secondary leukemia after a solid tumor in childhood according to the dose of epipodophyllotoxins and anthracyclines: A case-control study by the Societe Francaise d'Oncologie Pediatrique. J Clin Oncol 21: 1074-1081, 2003.

57. Vergnenegre A, Monnet I, Bizieux A, Bernardi M, Chiapa AM, Léna H, Chouaïd C and Robinet G: Open-label Phase II trial to evaluate safety and efficacy of second-line metronomic oral vinorelbine-atezolizumab combination for stage-IV non-small-cell lung cancer-VinMet Atezo trial, (GFPC ${ }^{\ddagger}$ 04-2017). Future Oncol 16: 5-10, 2020.

58. Platania M, Pasini F, Porcu L, Boeri M, Verderame F, Modena Y, Del Conte A, Nichetti F, Garassino MC, Martinetti A, et al: Oral maintenance metronomic vinorelbine versus best supportive care in advanced non-small-cell lung cancer after platinum-based chemotherapy: The MA.NI.LA. multicenter, randomized, controlled, phase II trial. Lung Cancer 132: 17-23, 2019.

59. Munzone $\mathrm{E}$ and Colleoni $\mathrm{M}$ : Clinical overview of metronomic chemotherapy in breast cancer. Nat Rev Clin Oncol 12: 631-644, 2015.

60. de Castro G, Puglisi F, de Azambuja E, El Saghir NS and Awada A: Angiogenesis and cancer: A cross-talk between basic science and clinical trials (the 'do ut des' paradigm). Crit Rev Oncol Hemat 59: 40-50, 2006

61. Kerbel RS: A decade of experience in developing preclinical models of advanced- or Early-stage spontaneous metastasis to study antiangiogenic drugs, metronomic chemotherapy, and the tumor microenvironment. Cancer J 21: 274-283, 2015.

62. Maiti R: Metronomic chemotherapy.JPharmacol Pharmacother 5 : 186-192, 2014

63. Bocci G, Nicolaou KC and Kerbel RS: Protracted low-dose effects on human endothelial cell proliferation and survival in vitro reveal a selective antiangiogenic window for various chemotherapeutic drugs. Cancer Res 62: 6938-6943, 2002.

64. Grant DS, Williams TL, Zahaczewsky $M$ and Dicker AP Comparison of antiangiogenic activities using paclitaxel (taxol) and docetaxel (taxotere). Int J Cancer 104: 121-129, 2003.

65. Bertolini F, Paul S, Mancuso P, Monestiroli S, Gobbi A, Shaked Y and Kerbel RS: Maximum tolerable dose and low-dose metronomic chemotherapy have opposite effects on the mobilization and viability of circulating endothelial progenitor cells. Cancer Res 63: 4342-4346, 2003.

66. Mpekris F, Baish JW, Stylianopoulos T and Jain RK: Role of vascular normalization in benefit from metronomic chemotherapy. Proc Natl Acad Sci USA 114: 1994-1999, 2017.

67. Sarmiento R and Gasparini G: Antiangiogenic metronomic chemotherapy. Onkologie 31: 161-162, 2008.

68. Laquente B, Vinals F and Germa JR: Metronomic chemotherapy: An antiangiogenic scheduling. Clin Transl Oncol 9: 93-98, 2007.

69. Pasquier E, Kavallaris M and Andre N: Metronomic chemotherapy: New rationale for new directions. Nat Rev Clin Oncol 7: 455-465, 2010.

70. Andre N, Carre M and Pasquier E: Metronomics: Towards personalized chemotherapy? Nat Rev Clin Oncol 11: 413-431, 2014.

71. Ghiringhelli F, Menard C, Puig PE, Ladoire S, Roux S, Martin F, Solary E, Le Cesne A, Zitvogel L and Chauffert B: Metronomic cyclophosphamide regimen selectively depletes CD4+CD25+ regulatory $\mathrm{T}$ cells and restores $\mathrm{T}$ and NK effector functions in end stage cancer patients. Cancer Immunol Immunother 56 : 641-648, 2007.

72. Shaked Y, Pham E, Hariharan S, Magidey K, Beyar-Katz O, Xu P, Man S, Wu FT, Miller V, Andrews D and Kerbel RS: Evidence Implicating immunological host effects in the efficacy of metronomic low-dose chemotherapy. Cancer Res 76: 5983-5993, 2016
73. Kosmaczewska A, Ciszak L, Potoczek S and Frydecka I: The significance of Treg cells in defective tumor immunity. Arch Immunol Ther Exp (Warsz) 56: 181-191, 2008.

74. Hao YB, Yi SY, Ruan J, Zhao L and Nan KJ: New insights into metronomic chemotherapy-induced immunoregulation. Cancer Lett 354: 220-226, 2014

75. Banissi C, Ghiringhelli F, Chen L and Carpentier AF: Treg depletion with a low-dose metronomic temozolomide regimen in a rat glioma model. Cancer Immunol Immunother 58: 1627-1634, 2009.

76. Ghiringhelli F, Ménard C, Martin F and Zitvogel L: The role of regulatory $\mathrm{T}$ cells in the control of natural killer cells: Relevance during tumor progression. Immunol Rev 214: 229-238, 2006.

77. Kodumudi KN, Woan K, Gilvary DL, Sahakian E, Wei S and Djeu JY: A novel chemoimmunomodulating property of docetaxel: Suppression of myeloid-derived suppressor cells in tumor bearers. Clin Cancer Res 16: 4583-4594, 2010.

78. Sevko A, Michels T, Vrohlings M, Umansky L, Beckhove P, Kato M, Shurin GV, Shurin MR and Umansky V: Antitumor effect of paclitaxel is mediated by inhibition of myeloid-derived suppressor cells and chronic inflammation in the spontaneous melanoma model. J Immunol 190: 2464-2471, 2013.

79. Vincent J, Mignot G, Chalmin F, Ladoire S, Bruchard M, Chevriaux A, Martin F, Apetoh L, Rébé C and Ghiringhelli F: 5-Fluorouracil selectively kills tumor-associated myeloid-derived suppressor cells resulting in enhanced $\mathrm{T}$ cell-dependent antitumor immunity. Cancer Res 70: 3052-3061, 2010.

80. Bracci L, Schiavoni G, Sistigu A and Belardelli F: Immune-based mechanisms of cytotoxic chemotherapy: Implications for the design of novel and rationale-based combined treatments against cancer. Cell Death Differ 21: 15-25, 2014.

81. Kareva I, Waxman DJ and Lakka Klement G: Metronomic chemotherapy: An attractive alternative to maximum tolerated dose therapy that can activate anti-tumor immunity and minimize therapeutic resistance. Cancer Lett 358: 100-106, 2015.

82. Martin-Padura I, Marighetti P, Agliano A, Colombo F, Larzabal L, Redrado M, Bleau AM, Prior C, Bertolini F and Calvo A: Residual dormant cancer stem-cell foci are responsible for tumor relapse after antiangiogenic metronomic therapy in hepatocellular carcinoma xenografts. Lab Invest 92: 952-966, 2012.

83. Folkins C, Man S, Xu P, Shaked Y, Hicklin DJ and Kerbel RS: Anticancer therapies combining antiangiogenic and tumor cell cytotoxic effects reduce the tumor stem-like cell fraction in glioma xenograft tumors. Cancer Res 67: 3560-3564, 2007.

84. Vives M, Ginesta MM, Gracova K, Graupera M, Casanovas O, Capellà G, Serrano T, Laquente B and Viñals F: Metronomic chemotherapy following the maximum tolerated dose is an effective anti-tumour therapy affecting angiogenesis, tumour dissemination and cancer stem cells. Int J Cancer 133: 2464-2472, 2013.

85. Yan H, Chen X, Zhang QP, Qin J, Li H, Liu C, Calhoun-Davis T, Coletta LD, Klostergaard J, Fokt I, et al: Drug-tolerant cancer cells show reduced tumor-initiating capacity: Depletion of CD44(+) cells and evidence for epigenetic mechanisms. PLoS One 6: e24397, 2011

86. Aguirre-Ghiso JA: Models, mechanisms and clinical evidence for cancer dormancy. Nat Rev Cancer 7: 834-846, 2007.

87. Udagawa T: Tumor dormancy of primary and secondary cancers. Apmis 116: 615-628, 2008.

88. Natale G and Bocci G: Does metronomic chemotherapy induce tumor angiogenic dormancy? A review of available preclinical and clinical data. Cancer Lett 432: 28-37, 2018.

89. Schirrmacher V: T-cell immunity in the induction and maintenance of a tumour dormant state. Semin Cancer Biol 11: 285-295, 2001.

90. Weir G, Hrytsenko O, Stanford M, Karkada M, Berinstein N and Mansour M: Abstract 2508: Multi-modal treatment with peptide vaccine, metronomic cyclophosphamide and anti-PD1 monoclonal antibody provides effective control of tumors in multiple models. Cancer Res: 75, 2015 doi: 10.1158/1538-7445. AM2015-2508.

91. Rajasekaran T, Ng QS, Tan DS, Lim WT, Ang MK, Toh CK, Chowbay B, Kanesvaran R and Tan EH: Metronomic chemotherapy: A relook at its basis and rationale. Cancer Lett 388: 328-333, 2017.

92. Eichhorn ME, Ischenko I, Luedemann S, Strieth S, Papyan A, Werner A, Bohnenkamp H, Guenzi E, Preissler G, Michaelis U, et al: Vascular targeting by EndoTAG-1 enhances therapeutic efficacy of conventional chemotherapy in lung and pancreatic cancer. Int J Cancer 126: 1235-1245, 2010. 
93. Panigrahy D, Kaipainen A, Butterfield CE, Chaponis DM, Laforme AM, Folkman J and Kieran MW: Inhibition of tumor angiogenesis by oral etoposide. Exp Ther Med 1: 739-746, 2010.

94. Jones BS, Jerome MS, Miley D, Jackson BE, DeShazo MR Reddy VV, Singh KP, Brown OC and Robert F: Pilot phase II study of metronomic chemotherapy in combination with bevacizumab in patients with advanced non-squamous non-small cell lung cancer. Lung Cancer 106: 125-130, 2017.

95. Giorgio CG, Giuffrida D, Pappalardo A, Russo A, Santini D, Salice P, Blanco G, Castorina S, Failla G and Bordonaro R: Oral temozolomide in heavily pre-treated brain metastases from non-small cell lung cancer: Phase II study. Lung Cancer 50: 247-254, 2005
96. Banna GL, Camerini A, Bronte G, Anile G, Addeo A, Rundo F, Zanghì G, Lal R and Libra M: Oral metronomic vinorelbine in advanced non-small cell lung cancer patients unfit for chemotherapy. Anticancer Res 38: 3689-3697, 2018.

97. Bilir C, Durak S, Kizilkaya B, Hacibekiroglu I, Nayir E and Engin $\mathrm{H}$ : Efficacy of metronomic vinorelbine in elderly patients with advanced non-small-cell lung cancer and poor performance status. Curr Oncol 24: e199-e204, 2017.

98. Mencoboni M, Filiberti RA, Taveggia P, Del Corso L, Del Conte A, Covesnon MG, Puccetti C, Donati S, Auriati L, Amoroso D and Camerini A: Safety of first-line chemotherapy with metronomic single-agent oral vinorelbine in elderly patients with NSCLC. Anticancer Res 37: 3189-3194, 2017. 